\title{
Specificity in the Projections of Prefrontal and Insular Cortex to Ventral Striatopallidum and the Extended Amygdala
}

\author{
Sheila M. Reynolds and Daniel S. Zahm \\ Department of Pharmacological and Physiological Science, Saint Louis University School of Medicine, St. Louis, Missouri 63104
}

\begin{abstract}
The basal forebrain functional-anatomical macrosystems, ventral striatopallidum, and extended amygdala are innervated by substantially coextensive distributions of neurons in the prefrontal and insular cortex. This suggests two alternative organizational schemes: convergent, in which a given cortical area projects exclusively to only one of these macrosystems and divergent, in which a given cortical area innervates both forebrain macrosystems. To examine the underlying organization and possibly discriminate between these alternatives, rats were injected with two retrograde tracers in different parts of ventral striatopallidum or extended amygdala (homotypic injection pairs) or with one tracer in each macrosystem (heterotypic). The prefrontal and insular cortex was evaluated microscopically for overlap of retrograde labeling and double labeling of neurons. Homotypic injection pairs in the ventral striatum and extended amygdala produced extensive overlap of retrogradely labeled neurons and significant double labeling, suggesting that cortical projections spread broadly within macrosystems. In contrast, heterotypic injection pairs produced significant overlap of retrograde labeling but negligible double labeling, indicating that ventral striatopallidum and extended amygdala receive inputs from separate sets of prefronto- and insular cortical neurons. The caudomedial shell of the nucleus accumbens, a supposed "transition" zone between striatopallidum and extended amygdala, had extended amygdala-like afferents but produced few double-labeled neurons and these only when paired with ventral striatopallidum. The data suggest that a modular organization of the basal forebrain, with postulated independent information processing by the ventral striatopallidal and extended amygdala macrosystems, is reflected in a corresponding segregation of output neurons in the prefrontal and insular cortices.
\end{abstract}

Key words: basal forebrain; macrosystem; accumbens; reward; striatum; caudomedial shell

\section{Introduction}

Successful behavior requires flexibility, i.e., that timely adaptive actions and coordinated autonomic and neuroendocrine discharges be deftly turned on and off in response to coinciding, conflicting, and changing internal dictates and external circumstances (Mesulam, 1990; Holstege et al., 1996; Aston-Jones et al., 1999). The relevant processes are modulated by emotions (Holstege, 1992) and are frequently lost in neurological and neuropsychiatric disorders (Eslinger and Grattan, 1993; Wolters, 2000; McDonald et al., 2002; Habib, 2004).

Behavioral flexibility is subserved by the interconnections of the cerebral cortex and subcortical structures (MacLean, 1989; Napier et al., 1991; Kalivas and Barnes, 1993; Holstege et al., 1996; McGinty, 1999). Among extant models describing relevant connectional relationships (Alheid and Heimer, 1988; Holstege, 1989, 1992; Swanson, 2000, 2003; Alheid, 2003; Heimer, 2003), one features basal forebrain "functional-anatomical macrosys-

Received March 29, 2005; revised Nov. 3, 2005; accepted Nov. 6, 2005.

This work was supported by United States Public Health Service National Institutes of Health (NIH) Grant NS 23805 and NIH-National Institute on Drug Abuse Fellowship F32 DA016011 (S.M.R.). We thank Prof. Lennart Heimer for helpful comments on a previous version of this manuscript and M. Panneton for access to the Neurolucida system.

Correspondence should be addressed to either Daniel S. Zahm or Sheila M. Reynolds, Department of Pharmacological and Physiological Science, Saint Louis University School of Medicine, 1402 South Grand Boulevard, St. Louis, M0 63104.E-mail:zahmds@slu.edu or reynolsm@slu.edu.

D01:10.1523/JNEUROSCI.3432-05.2005

Copyright $\odot 2005$ Society for Neuroscience 0270-6474/05/2511757-11\$15.00/0 tems," e.g., striatopallidum (Heimer and Wilson, 1975), extended amygdala (Alheid and Heimer, 1988), and the hippocampal-septal system (Alheid and Heimer, 1988; Swanson, 2000), which are said to receive specific information primarily from the cortex and project back to cortex via connections with thalamocortical and other corticopetal systems and to diencephalic and brainstem motor effectors. Specific cytoarchitectonic and neurochemical differentiations characterize macrosystems (Alheid and Heimer, 1988; Heimer et al., 1997b; Zahm et al., 2003), consistent with the hypothesis that they are independent information-processing units (Zahm, 2005). What information is processed by macrosystems, however, and how inputs that deliver this information are structured is not well understood.

It is well established, however, that ventral striatopallidum and extended amygdala essentially are innervated by the same cortical areas (McGeorge and Faull, 1989; Groenewegen et al., 1990, 1997; Berendse et al., 1992; Brog et al., 1993; McIntyre et al., 1996; McDonald et al., 1996, 1999; McDonald, 1998; Shi and Cassell, 1998a; Zahm, 1998, 2000, 2005), consistent with two organizational schemes for cortex-to-macrosystem information transfer. In one model, a set of cortical projections reflecting outputs from a functionally or anatomically defined network (Mesulam, 1990; Carmichael and Price, 1995, 1996; Öngür and Price, 2000; Jones et al., 2005) selectively innervates a specified macrosystem, which may get converging inputs from several such cortical networks. In the other, network projections would 
Table 1. Stereotaxic coordinates ${ }^{a}$ for injection sites

\begin{tabular}{llll}
\hline & AP & ML & DV \\
\hline $\mathrm{CPu}$ & +0.7 & -2.0 & -5.0 \\
$\mathrm{AcbC}$ & +1.5 & -1.4 & -6.5 \\
$\mathrm{AcbS}$ & +1.0 & -1.0 & -6.7 \\
$\mathrm{BST}$ & -0.4 & -1.8 & -6.7 \\
$\mathrm{CeA}$ & -2.5 & -4.3 & -6.7 \\
\hline
\end{tabular}

an millimeters relative to bregma, using flat-skull techniques.

AP, Anteroposterior; ML, mediolateral; DV, dorsoventral.

diverge to multiple macrosystems, thus subjecting any given set of outputs to several forms of subcortical processing.

The likelihood that a cortical output neuron projects to more than one macrosystem is greater in the "divergence" model, which presents a potential means to validate one model over the other. This led us to make pairs of ipsilateral injections either with one tracer in extended amygdala and another in ventral striatum (heterotypic) or with two injections in different parts of the same macrosystem (homotypic). Cases were evaluated for degree of overlap of retrograde labeling and double labeling of cortical neurons with descriptions limited in this paper to the prefrontal and insular cortex. Labeling in the rest of the cortex and subcortical structures will be described in forthcoming papers.

\section{Materials and Methods}

Unless otherwise specified, all chemicals and reagents were from Sigma (St. Louis, MO).

Injections. Under deep anesthesia [1.6 ml/kg mixture comprising $45 \%$ ketamine $(100 \mathrm{mg} / \mathrm{ml}), 35 \%$ xylazine $(20 \mathrm{mg} / \mathrm{ml})$, and $20 \%$ isotonic saline given intraperitoneally], a total of 53 male Sprague Dawley rats (Harlan, Indianapolis, IN) weighing between 240 and $320 \mathrm{~g}$ at the time of surgery received two retrograde tracer injections into the same hemisphere. Fluoro-Gold (FG; Fluorochrome, Denver, CO) and cholera toxin subunit $\beta$ (CT $\beta$; List Biological Laboratories, Campbell, CA) were dissolved in $0.067 \mathrm{M}$ cacodylate buffer and $0.01 \mathrm{M}$ sodium phosphate buffer (SPB), pH 7.5, respectively. Both tracers were used at a concentration of $1 \%$ and injected iontophoretically with positive pulses $(7 \mathrm{~s}$ on and $7 \mathrm{~s}$ off for $15 \mathrm{~min})$ at $1 \mu \mathrm{A}(\mathrm{FG})$ and $3 \mu \mathrm{A}(\mathrm{CT} \beta)$ through $1.0 \mathrm{~mm}$ pipettes pulled to tip diameters of $15-20 \mu \mathrm{m}$. Sites that received FG and CT $\beta$ injections were reversed in alternate cases. Five sites specifically targeted for injection are given with their stereotaxic coordinates in Table 1, and the combinations of these sites constituting the six evaluated injection pairs are shown in Table 2.

Three to $5 \mathrm{~d}$ after surgery, rats were reanesthetized and killed by vascular perfusion, first with a brief rinse of sodium PBS containing $0.5 \%$ procaine $\mathrm{HCl}$ and $2.5 \%$ sucrose, followed for 20 min with $0.1 \mathrm{M} \mathrm{SPB}, \mathrm{pH}$ 7.4 , containing $4 \%$ paraformaldehyde and $2.5 \%$ sucrose. The brains were immediately removed, stored overnight in fresh fixative, and then transferred to SPB containing 25\% sucrose. Five adjacent series of $50 \mu \mathrm{m}$ frozen sections were cut in the coronal plane with a sliding microtome and stored at $-20^{\circ} \mathrm{C}$ in $0.1 \mathrm{~m}$ phosphate buffer, $\mathrm{pH} 7.4$, containing $30 \%$ ethylene glycol and $30 \%$ sucrose.

Immunoperoxidase processing. Sections were retrieved from the freezer, rinsed in SPB, immersed for $15 \mathrm{~min}$ in an aqueous solution containing $1 \%$ sodium borohydride, and then, to completely remove it, rinsed repeatedly in SPB. The sections were immersed for $1 \mathrm{~h}$ in $0.1 \mathrm{M} \mathrm{SPB}$ containing $0.2 \%$ Triton X-100 (SPB-Triton) and 5\% normal donkey serum (NDS; Jackson ImmunoResearch, West Grove, PA) and were then immersed overnight at room temperature with gentle agitation in the same carrier solution containing a 1:8000 dilution of rabbit anti-FG antibody (Chemicon, Temecula, CA). The sections were then rinsed in SPB-Triton and immersed for $1 \mathrm{~h}$ in the same carrier solution containing a 1:200 dilution of biotinylated anti-rabbit IgG (Jackson ImmunoResearch). Another series of rinses preceded immersion of the sections for $1 \mathrm{~h}$ in the same carrier solution containing a 1:200 dilution of avidin-biotin-peroxidase complex (ABC; Vector Laboratories, Burlingame, CA), after which the sections were again rinsed and then reacted for $10 \mathrm{~min}$ in a nickel-diaminobenzidine (DAB) solution containing $0.015 \%$ DAB, $0.4 \%$ nickel ammonium sulfate, and $0.006 \% \mathrm{H}_{2} \mathrm{O}_{2}$ in $0.025 \mathrm{M}$ Tris- $\mathrm{HCl}$ buffer, $\mathrm{pH}$ 8.0. The sections were rinsed and then immersed overnight with agitation in the same carrier solution containing a 1:3000 dilution of goat anti-CT $\beta$ antibody (List Biological Laboratories). After more rinses, the sections were exposed for $1 \mathrm{~h}$ in the same carrier solution with intervening rinses to a 1:100 dilution of donkey anti-goat IgG (Jackson ImmunoResearch) and a 1:3000 dilution of goat peroxidase-antiperoxidase (Cappel Laboratories, Durham, NC). After rinsing in SPB without Triton, the sections were then placed in $0.05 \mathrm{M} \mathrm{SPB}, \mathrm{pH} 7.4$, containing $0.05 \% \mathrm{DAB}, 0.2 \% \quad \beta$-D-glucose, $0.04 \%$ ammonium chloride, and $0.0005 \%$ glucose oxidase and were thereafter rinsed again in SPB.

A series of sections from each case was also processed to exhibit substance P immunoreactivity to show subcortical neuroanatomical organization. The sections were then immersed in the conditions described above in SPB-Triton containing the following: (1) 5\% NDS for $1 \mathrm{~h},(2)$ $5 \%$ NDS and a 1:3000 dilution of rabbit anti-substance P antibody (ImmunoStar, Hudson, WI) overnight, (3) a 1:200 dilution of biotinylated donkey anti-rabbit IgG for $1 \mathrm{~h},(4) \mathrm{ABC}$ at 1:200 for $1 \mathrm{~h}$, and (5) nickel-DAB.

Immunofluorescence processing. Series of sections were immersed in succession at room temperature, with gentle agitation and intervening rinses in SPB-Triton containing the following: (1) 5\% NDS for $1 \mathrm{~h},(2)$ $5 \%$ NDS and a 1:8000 dilution of anti-FG antibody overnight, (3) a 1:200 dilution of biotinylated donkey anti-rabbit IgG for $1 \mathrm{~h}$, (4) a 1:200 dilution of avidin-Texas Red (excitation, $596 \mathrm{~nm}$; emission, $620 \mathrm{~nm}$; Jackson ImmunoResearch) for $1 \mathrm{~h}$, (5) 5\% NDS and a 1:3000 dilution of antiCT $\beta$ antibody overnight, and (6) a 1:100 dilution of donkey anti-sheepcyanine 2 (Cy2) conjugate (excitation, $492 \mathrm{~nm}$; emission, $510 \mathrm{~nm}$; Jackson ImmunoResearch) for $1 \mathrm{~h}$. The sections were then rinsed in SPB.

Microscopy. At the completion of processing, sections were mounted in rostrocaudal sequence on glass slides, air dried, dehydrated with alcohol, defatted with xylene, and coverslipped using either Permount (Fisher Scientific, St. Louis, MO) for peroxidase reactions or DPX (distyrene, tricresyl phosphate, and xylene; Fluka/Sigma-Aldrich, Steinhem, Germany) for fluorescence immunohistochemistry. The sections were visualized with a Nikon (Tokyo, Japan) Eclipse E600 microscope equipped for brightfield and fluorescence microscopy. For fluorescence, the microscope was equipped with a dual-band fluorescence filter set (Chroma Technology, Brattleboro, VT) with excitation bands at 480505 and $560-590 \mathrm{~nm}$ and emission bands at 505-545 and 600-650 nm, for green (Cy2) and red (Texas Red) fluorescence, respectively.

Injection sites. To localize the injection sites, images of selected substance P-immunoreacted sections were traced using the Neurolucida hardware-software platform (MicroBrightField, Williston, VT) to delineate structures, such as the central nucleus of the amygdala $(\mathrm{CeA})$, and boundaries between the nucleus accumbens shell and core, accumbens shell and bed nucleus of stria terminalis (BST), and bed nucleus stria terminalis and ventral pallidum (Zahm and Brog, 1992; Alheid et al., 1995). These outlines were superimposed on the images of adjacent sections immunoreacted for FG and CT $\beta$, and the positions of the injections were marked. This procedure was repeated for each section displaying a clearly visible injection, resulting in three to five serial portraits of each injection. The summary map of injections analyzed in this study (Fig. 1) shows only the largest profiles of injections (presumably nearest the injection centers). Distances between pairs of injection sites were estimated by transcribing the centers of the two injections to appropriate spots in the atlas of Paxinos and Watson (1998) and using the coordinates given therein to carry out the appropriate trigonometric calculations.

Analysis of retrograde labeling. Retrogradely labeled neurons exhibiting Cy2, Texas Red, and both fluorophores were visualized in every other section as green, red, and yellow, respectively, and plotted with the aid of the Neurolucida hardware-software imaging platform (MicroBrightField). Four and nine plotted sections, respectively, were used to quantify prefrontal and insular labeling. Evaluated sections from each of three cases for each injection pair were matched for anterior-posterior levels. The plots were quantified with NeuroExplorer software (MicroBrightField) to determine numbers of single- and double-labeled neurons in 
A. CPu and AcbC
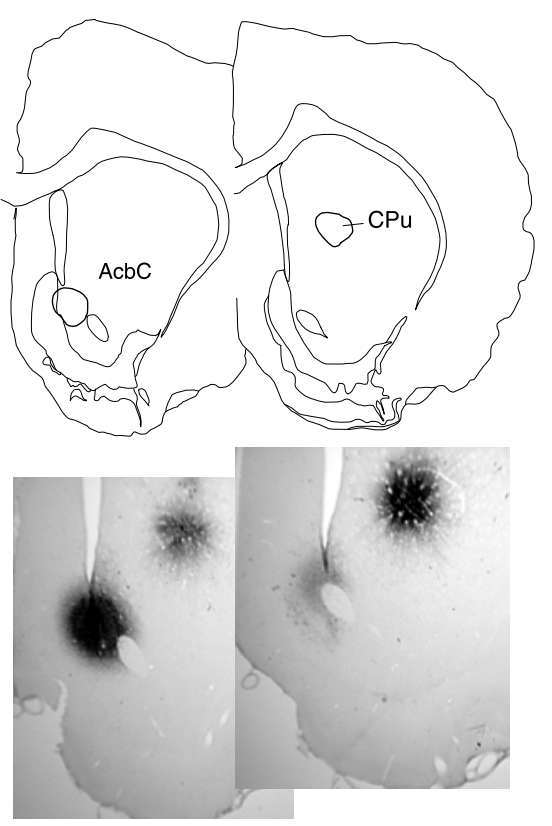

D. BST and AcbS

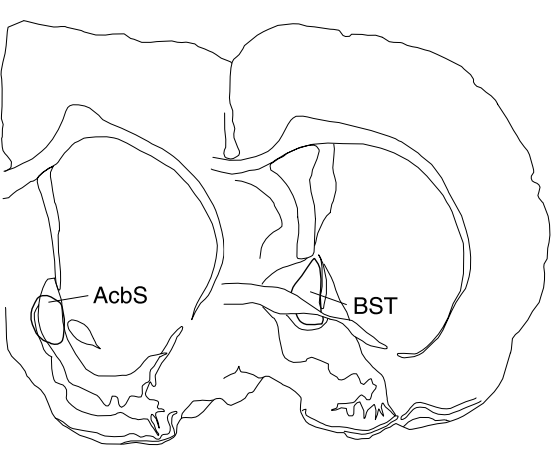

B. CPu and AcbS
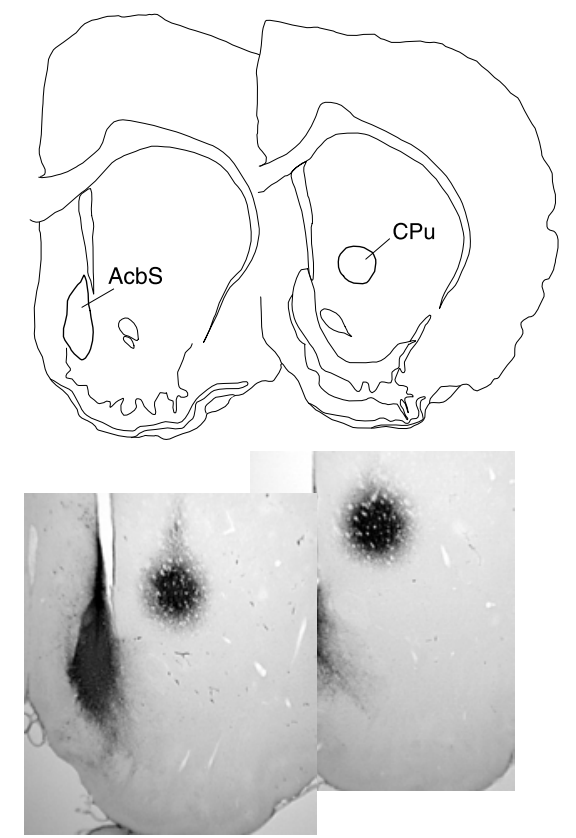

E. CeA and AcbS

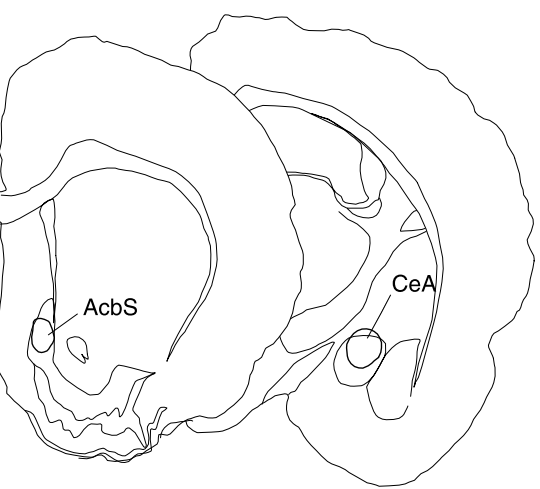

C. CPu and BST
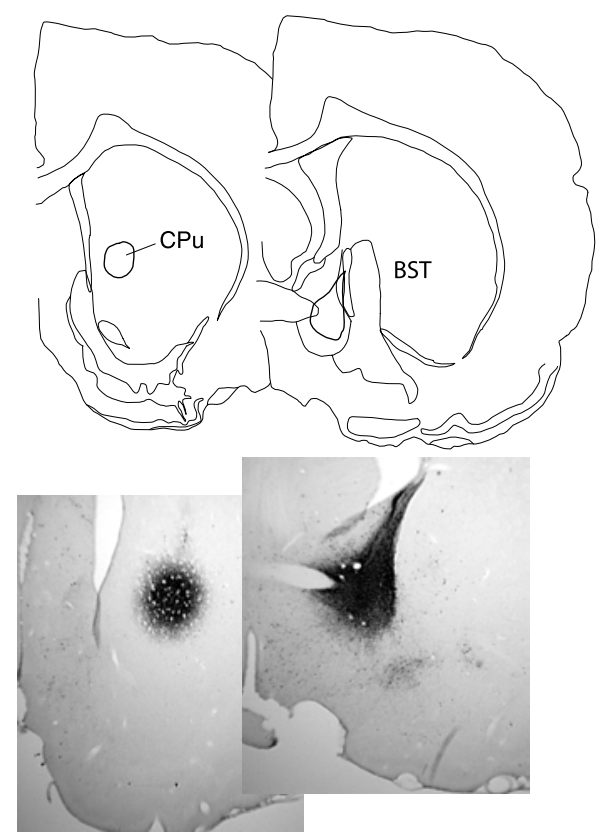

F. CeA and BST

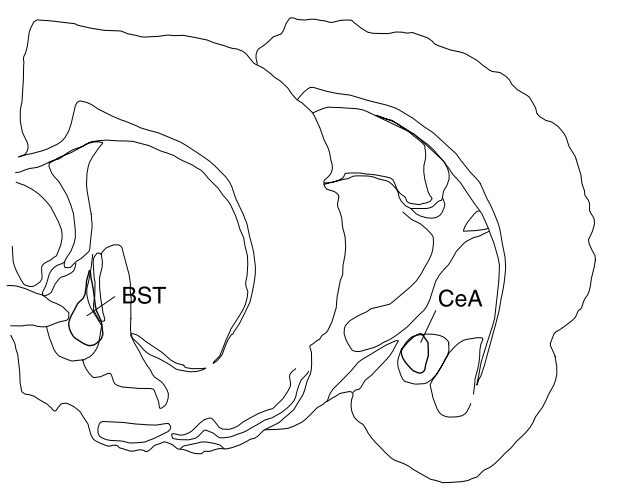

Figure 1. Representative examples of each of the six pairs of injections of retrograde tracers evaluated in this study. $A, C P u$ and $A c b C . B, C P u$ and $A c b S$. C, CPu and the dorsolateral subdivision of the BST. D, BST and AcbS. E, CeA and AcbS. F, CeA and BST. Photomicrographs corresponding to $A-C$ are shown directly below the respective panels.

particular structures identified with reference to substance P immunoreactivity. Data normalized as percentage of total were used to compare cortical subdivisions.

Immunofluorescence controls. To confirm the fidelity of the bright yellow label as an indicator of double labeling, i.e., to validate the use of the dual-band filter, images acquired with it were compared with merged digital images generated using single-band filter blocks. This was done with both the Nikon E600 fluorescence microscope and a Bio-Rad (Hercules, CA) MRC 1024 confocal microscope. To exclude visualization of neurons stacked in the $z$-axis, one level from a $z$-series of $0.2 \mu \mathrm{m}$ confocal images was selected for presentation. Images were merged using Confocal Assistant or NIH ImageJ software. When necessary, minimal digital adjustments were made to equilibrate red and green background signals.

Nomenclature: prefrontal cortex. Four divisions of the medial prefrontal cortex were considered: anterior cingulate plus medial precentral, prelimbic, infralimbic, and dorsal peduncular. Whether the infralimbic or dorsal peduncular cortices are to be regarded as prefrontal cortex has been questioned because they are said not to receive projections from the thalamic mediodorsal nucleus (Krettek and Price, 1977; Van Eden and Uylings, 1985). However, inclusion of the infralimbic cortex and dorsal peduncular area in analyses of prefrontal cortex, attributable to their continuity with the prelimbic area, is a convention that will be followed here. Lateral prefrontal cortex, as considered here, comprises the agranular insular cortex rostral to the genu of the corpus callosum and was not partitioned as ventral and dorsal parts. Orbital cortex was regarded as comprising three subregions: ventral, lateral, and dorsolateral. Because the caudal continuation of the ventral orbital area is indistinguishable from infralimbic cortex on the basis of cytoarchitectonics (Van Eden and Uylings, 1985), ventral orbital cortex was included with the infralimbic cortex as part of the medial frontal region (Berendse et al., 1992).

Nomenclature: insular cortex. The insular cortex occupies the dorsal bank of the rhinal fissure between the lateral prefrontal area rostrally and the perirhinal cortex caudally, extending roughly between bregma +2.0 and $-3.8 \mathrm{~mm}$. Three subdivisions of the insular cortex, listed from dorsal to ventral, include granular, dysgranular, and agranular. The insular cortex also is generally divided into anterior and posterior parts. However, in view of disagreements as to where the split occurs (McIntyre et al., 1996; McDonald, 1998; Paxinos and Watson, 1998; Shi and Cassell, 1998a; Burwell, 2001), this study will consider three anteroposterior parts of the insular cortex. Anterior will refer to the insular cortical continuation of the lateral prefrontal cortex (between bregma +2.0 and $+0.5 \mathrm{~mm}$ ). Posterior will refer to insular cortex between the emergence of the hippocampal dentate gyrus and caudalmost caudate-putamen $(\mathrm{CPu})$ (between bregma -1.50 and $-3.80 \mathrm{~mm}$ ) and may include a rostral part of the perirhinal cortex (McIntyre et al., 1996; Paxinos and Watson, 1998). The middle part of the insular cortex, between these, occupies levels where the boundary between anterior and posterior insular cortex is debated. 
Table 2. Injection sites illustrated in Figure 1

\begin{tabular}{|c|c|c|c|c|c|}
\hline Case & $\mathrm{CPu}$ & $\mathrm{AcbC}$ & AcbS & BST & CeA \\
\hline \multicolumn{6}{|c|}{ CPu-AcbC (2.0 \pm 0.1$)$ (Fig. 1A) } \\
\hline 04109 & $\mathrm{CT} \beta$ & FG & & & \\
\hline 04114 & $\mathrm{FG}$ & $\mathrm{CT} \beta$ & & & \\
\hline 04129 & FG & СТ $\beta$ & & & \\
\hline \multicolumn{6}{|c|}{ CPu-AcbS (1.7 \pm 0.3$)($ Fig. 1B) } \\
\hline 03160 & FG & & $\mathrm{CT} \beta$ & & \\
\hline 03291 & СТ $\beta$ & & FG & & \\
\hline 04108 & FG & & $\mathrm{CT} \beta$ & & \\
\hline \multicolumn{6}{|c|}{ CPu-BST $(2.1 \pm 0.1)$ (Fig. 1C) } \\
\hline 04040 & СТ $\beta$ & & & FG & \\
\hline 04054 & FG & & & $\mathrm{CT} \beta$ & \\
\hline 04111 & FG & & & $\mathrm{CT} \beta$ & \\
\hline \multicolumn{6}{|c|}{ BST-AcbS (1.2 \pm 0.1$)$ (Fig. 1D) } \\
\hline 03296 & & & FG & $\mathrm{CT} \beta$ & \\
\hline 03308 & & & FG & $\mathrm{CT} \beta$ & \\
\hline 03310 & & & FG & $\mathrm{CT} \beta$ & \\
\hline \multicolumn{6}{|c|}{ CeA-AcbS $(4.7 \pm 0.2)($ Fig. 1E) } \\
\hline 04014 & & & $\mathrm{CT} \beta$ & & FG \\
\hline 04073 & & & $\mathrm{FG}$ & & $\mathrm{CT} \beta$ \\
\hline 04119 & & & $\mathrm{CT} \beta$ & & $\mathrm{FG}$ \\
\hline \multicolumn{6}{|c|}{ CeA-BST $(3.5 \pm 0.1)$ (Fig. 1F) } \\
\hline 04013 & & & & $\mathrm{CT} \beta$ & FG \\
\hline 04024 & & & & FG & $\mathrm{CT} \beta$ \\
\hline 04026 & & & & СТ $\beta$ & $\mathrm{FG}$ \\
\hline
\end{tabular}

Values in parentheses are the mean \pm SEM (in mM) between the two injection centers $(n=3)$.

Statistics. Where required, numbers of retrogradely labeled neurons were initially compared with one-way ANOVAs followed, as necessary, by post hoc Bonferroni's tests. Subregional distributions of labeled cells were evaluated by two-way ANOVAs for percentage of labeled cells from each injection site located within each subregion. Significant main effects were tested with one-way ANOVAs followed, as necessary, by Bonferroni's post hoc tests. Single and double labeling were analyzed separately.

\section{Results}

Injection sites

Ventral striatopallidal injections were located in the rostral ventromedial quadrant of the $\mathrm{CPu}$ (Fig. $1 A-C$ ), which is regarded as ventral striatum on the basis of connections (Kelley et al., 1982), and at the midrostrocaudal level of the nucleus accumbens core $($ AcbC) (Fig. 1A). Retrograde tracer injections were also placed in the dorsal caudomedial shell of the nucleus accumbens (AcbS) (Fig. $1 B, D, E)$. Extended amygdala injections were placed in the dorsolateral subnucleus of the BST (Fig. $1 C, D, F$ ) and CeA (Fig. $1 E, F)$. The BST injections usually also impinged, to a small degree, on medial parts of the bed nucleus and the CeA injections uniformly included the medial and lateral divisions of the CeA. Thus, injections into five structures paired in six different ways ( $n=3$ per pair) were evaluated (Fig. 1). The pairs included the following (Table 2): $\mathrm{CPu}-\mathrm{AcbC}$ (Fig. $1 A$ ), $\mathrm{CPu}-\mathrm{AcbS}$ (Fig. $1 B$ ), $\mathrm{CPu}-\mathrm{BST}$ (Fig. 1C), BST-AcbS (Fig. 1D), CeA-AcbS (Fig. 1E), and CeA-BST (Fig. $1 F$ ). The mean estimated distance between the centers of the injection pairs are shown in parentheses in Table 2. A seventh pair, involving the CeA and AcbC $(n=1)$, is also briefly described below.

\section{Fidelity of labeling visualization}

The fidelity of the dual-band filter for visualization of doublelabeled immunofluorescent neurons was validated with conventional single-band fluorescence filters (Fig. 2A,B) and confocal fluorescence (Fig. 2C) images. Cells that displayed even modest levels of excitation for Cy2 and Texas Red were bright yellow in
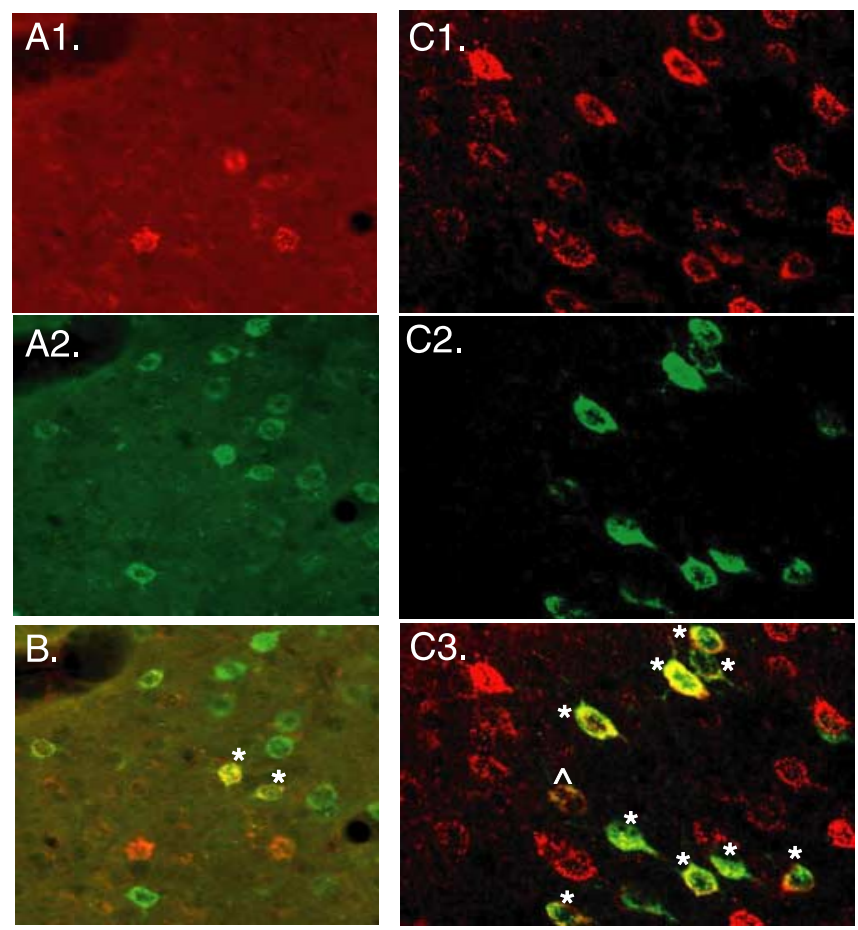

Figure 2. A1-C3, Photomicrographs showing single- and double-labeled cells in orbital cortex of a $\mathrm{CPu}-\mathrm{Acb}$ c case visualized by immunofluorescence with single-band filters $(\boldsymbol{A 1}, \boldsymbol{A 2})$, immunofluorescence with a dual-band filter $(\boldsymbol{B})$, and confocal microscopy (C1-C3). Doublelabeled cells (asterisks) are yellow. A double-labeled neuron in which the two fluorophores were unevenly exhibited appear slightly yellow (caret in (3). Note that $\boldsymbol{B}$ is not a merged image but rather shows, with the dual-band filter, the same field illustrated in $\mathbf{A} \mathbf{1}$ and $\mathbf{A} \mathbf{2}$ with single band filters. Alternatively, $\mathbf{C}$ is the merged image of $\mathbf{C}$ and $\mathbf{C}$.

dual-band filter images, and this was confirmed by merged images.

\section{Retrograde labeling}

Consistent with extant literature (see Introduction), each injection site evaluated here produced a focus of robust retrograde labeling in one or more parts of prefrontal and insular cortices (Figs. 3-5). Adjacent distributions of labeling, regardless from which particular injection pair, exhibited considerable overlap, however, and even distant foci of labeling were characterized at their peripheries by some overlap, e.g., in prelimbic cortex after paired $\mathrm{CPu}$ and AcbS injections (Fig. $3 B$ ). Thus, the singlelabeling data suggest that the prefrontal and insular cortical afferents of ventral striatopallidum and extended amygdala originate from distinct, but overlapping or interdigitating, sets of cortical neurons. Because the prefrontal and insular afferents of ventral striatopallidum and extended amygdala have not previously been compared directly in a single study, the following brief account will highlight only some major similarities and differences. Labeling produced by various injection pairs is mapped on diagrams of prefrontal and insular cortex in Figures 3 and 4, respectively. Figure 5 shows quantitative data describing the distributions of labeled neurons after injections in $\mathrm{CPu}(n=9)$, $\operatorname{AcbC}(n=3), \operatorname{AcbS}(n=9), \operatorname{BST}(n=9)$, and CeA $(n=6)$.

$\mathrm{CPu}$ and $\mathrm{AcbC}$ injections produced robust, widespread retrograde labeling in the dorsal and anterior parts of the medial prefrontal cortex, with the $\mathrm{CPu}$ and $\mathrm{AcbC}$ sites more densely labeling the anterior cingulate and prelimbic divisions, respectively (Figs. $3 A, 5 A-D)$. In contrast, BST, CeA, and AcbS injections mainly labeled ventral and posterior regions of medial prefrontal cortex, 


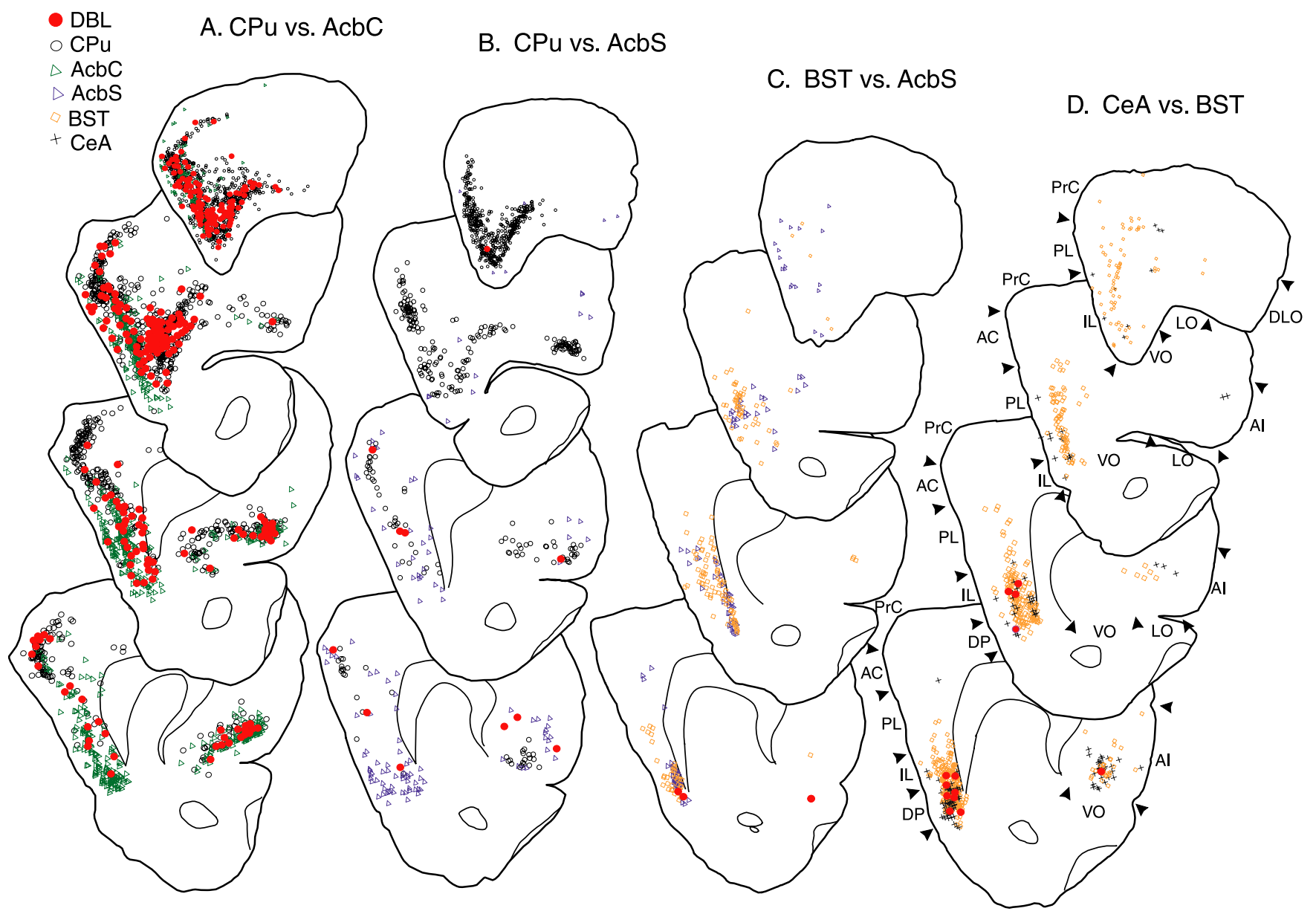

Figure 3. Plots of retrograde labeling in the prefrontal cortex produced in representative cases for each of the following injection pairs: $A, C P u-A c b C ; B, C P u-A c b S ; C, B S T-A c b S ; D, C e A-B S T$. DBL, Double-labeled neurons; AC, anterior cingulate; PrC, precentral cortex; PL, prelimbic; IL, infralimbic; DP, dorsal peduncular; Al, agranular insular; V0, ventral orbital; LO, lateral orbital; DLO, dorsolateral orbital.

including the infralimbic and dorsal peduncular divisions (Figs. $3 C, D, 5 A-D)$. CPu and AcbC injections also produced very robust labeling in orbital cortex, whereas negligible labeling was observed there after injections into BST, CeA, and AcbS (Figs. $3 A-D, 5 F, G)$. In lateral prefrontal cortex, AcbC and, to a lesser extent, $\mathrm{CPu}$ injections again produced the most labeling (Figs. $3 A, 5 E)$, although CeA injections did produce moderate retrograde labeling there (Figs. 3D,5E). BST and AcbS sites produced the least labeling in the lateral prefrontal cortex (Figs. $3 B-D, 5 E$ ).

$\mathrm{AcbC}$ and CeA injections produced robust labeling of about equivalent magnitudes in the insular cortex (Figs. $4 C, D, 5 H$ ), but in different distribution patterns (Fig. $5 J$ ). The other injection sites produced lesser amounts of insular cortical labeling, with that from AcbS being the least (Fig. 5H). The anterior part of the insular cortex was labeled after injections in all of these sites; however, CeA, BST, and AcbS sites labeled middle more strongly than posterior insular levels, whereas the $\mathrm{CPu}$ and $\mathrm{AcbC}$ sites more strongly targeted the posterior than middle insular cortex (Fig. $5 J$ ).

\section{Double labeling}

Patterns of double labeling are plotted in Figures 3 and 4 and graphed in Figure 6. The data indicate that homotypic injection pairs give rise to significant numbers of double-labeled neurons, whereas heterotypic pairs do not. Within the prefrontal cortex, only $\mathrm{CPu}-\mathrm{AcbC}$ pairs produced substantial double labeling (Fig.
$6 A-C)$, concentrated in orbital and medial prefrontal regions. In insular cortex, both CPu-AcbC (Fig. 6E) and CeA-BST (Fig. 6E) injection pairs produced significant double labeling, but with markedly different patterns of distribution at different rostrocaudal levels (Fig. 4, compare $A, D$; see also Fig. 6F). All heterotypic injection pairs displayed negligible numbers of double-labeled neurons in both prefrontal and insular cortices. Interestingly, $\mathrm{CPu}-\mathrm{AcbS}$ pairs produced double labeling in the prefrontal and insular cortex that, although not statistically significant with our $n$ values of 3 , was observed so consistently that we hesitate to regard it as negligible (Figs. $3 B, 4 B, 6 A, B, E$ ).

Double labeling was not simply a function of the strength of overlap of two distributions of retrogradely labeled neurons. On the contrary, the pattern of retrograde labeling in the ventral medial prefrontal cortex observed after AcbS injections virtually coincided with that produced by BST and CeA injections (Figs. $3 C, 4 C$ ), but negligible numbers of double-labeled neurons were produced by CeA-AcbS or BST-AcbS injection pairs. Furthermore, the magnitudes of double and single labeling were not correlated. Thus, although $\mathrm{CPu}$ and AcbC injections labeled two to three times more medial prefrontal neurons than did AcbS or $\mathrm{CeA}$ injections, $\mathrm{CPu}-\mathrm{AcbC}$ injection pairs produced $>40$ times more double-labeled cells than CeA-AcbS pairs. Nor can double labeling be attributed to the nearness of injection sites within a pair (Table 2). CeA-BST injection pairs produced significant double labeling, despite being separated on average by $3.5 \mathrm{~mm}$. In 
contrast, little double labeling was produced by BST-AcbS pairings, in which injection sites were occasionally contiguous and on average separated by only $1.2 \mathrm{~mm}$.

\section{AcbC-CeA injection pair}

In view of the substantial single labeling observed in the insular cortex after AcbC and $\mathrm{CeA}$ injections, one available AcbCCeA injection pair is briefly described (Fig. 7). Because immunofluorescence data for this case are unavailable, only immunoperoxidase results are presented. A large CT $\beta$ injection encompassed three-fourths of the medial AcbC extending nearly along its entire anteroposterior length. A larger FG injection occupied the anterior twothirds of the CeA and also significantly involved the globus pallidus and adjacent sublenticular region. Despite the large size of these injections, labeling in the prefrontal and insular cortices for this injection pair conformed to the basic patterns described above for AcbC and CeA injection sites. As predicted from single-labeling patterns observed in other cases, AcbC$\mathrm{CeA}$ injection pairs produced strong apparent overlap of labeling in insular cortex, which, on close inspection, was found to comprise distinct laminar distributions with AcbC and CeA single labeling occupying mainly superficial and deeper laminas, respectively. Negligible double labeling was observed in this case.

\section{Overlap and double labeling}

To directly compare the double labels elicited by different injection pairs, percentage of double-labeled neurons was plotted against percentage overlap of retrograde labeling generated by the different injection pairs (Fig. 8). Areas of overlap were defined operationally as containing $>10$ cells from each injection site of which at least $20 \%$ represented the weaker projection. Area of overlap was expressed as percentage of total area containing retrogradely labeled neurons. Percentage of double labeling was calculated as follows: ( $\%$ double labeling from injection $\mathrm{A}+\%$ from injection $\mathrm{B}) / 2$. In prefrontal cortex, $\mathrm{CPu}-\mathrm{AcbC}$ pairs produced greater overlap and double labeling $(22 \%)$ than other injection pairs, whereas CeA-BST pairs produced only greater overlap. Within insular cortex, both $\mathrm{CPu}-\mathrm{AcbC}$ and CeA-BST pairs exhibited significant overlap and double labeling ( $\mathrm{CPu}-\mathrm{Acb}, 22 \%$; CeA-BST, 10\%).

\section{Discussion}

Significant numbers of double-labeled neurons were observed when two injections occupied either ventral striatopallidum or extended amygdala, indicating that some cortical afferents spread quite widely within macrosystems. In contrast, double-labeled neurons were absent in prefrontal and insular cortices after placement of one injection in ventral striatopallidum and the other in extended amygdala, indicating that cortical neurons project only to one of these macrosystems. This observation fits with the idea that information processing mechanisms are segregated in basal forebrain macrosystems and actually extends the concept by suggesting that segregation is already present in cortical output systems. This, in turn, leads to a hypothesis that functionally or anatomically differentiated cortical networks engage specific subcortical mechanisms via projections to designated macrosystems. The data, however, leave open the possibility that separate subsets of neurons within a cortical network may systematically target different macrosystems. For example, Price and colleagues have reported that subdivisions within the neuroanatomically defined "orbital" and "medial" prefrontocortical networks (Carmichael et al., 1996) can be identified on the basis of projections to specific hypothalamic regions (Floyd et al., 2001) and distinct longitudinal columns in the periaqueductal gray (Floyd et al., 2000). In view of such findings, it would seem premature to presume that double-labeled neurons associated in this study with different homotypic injection pairs necessarily represent different putative cortical networks, as opposed to different parts of the same networks. It would be useful in this regard to consider whether such neurons are segregated within identified cortical columns, which are regarded as functional units of cortical networks (Hubel and Wiesel, 1962; Mountcastle, 2003). However, although cortical columns have been described in primate prefrontal cortex (Arikuni et al., 1983; Bugbee and Goldman-Rakic, 1983), to our knowledge there has as yet been no functional or anatomical designation of such units in rodent prefrontal or insular cortical regions (Carmichael et al., 1995, 1996; Floyd et al., 2000, 2001; Jones et al., 2005).

\section{Distinct cortical afferentation of ventral striatopallidum and extended amygdala}

The present data support segregation of cortical afferents in ventral striatopallidum and extended amygdala not only by virtue of the absence of heterotypic double labeling but also with respect to the observed patterns of single labeling. The prefrontocortical 


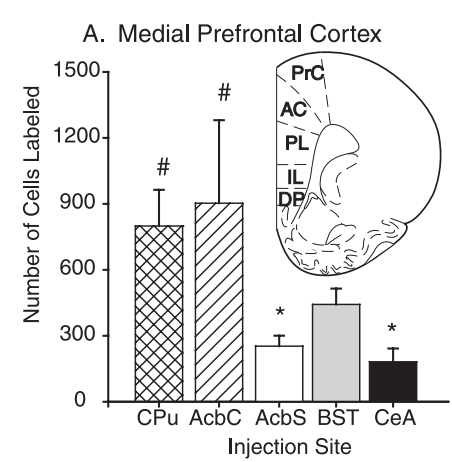

D. Infralimbic Cortex
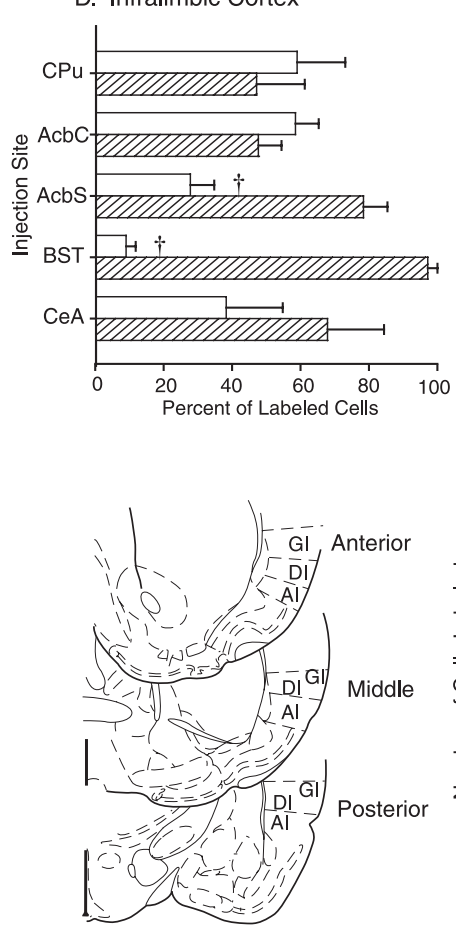

B. Medial Prefrontal by Subregion
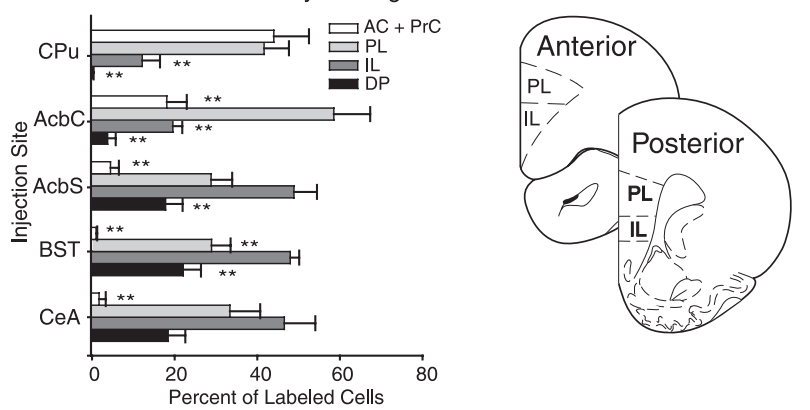

E. Lateral Prefrontal Cortex
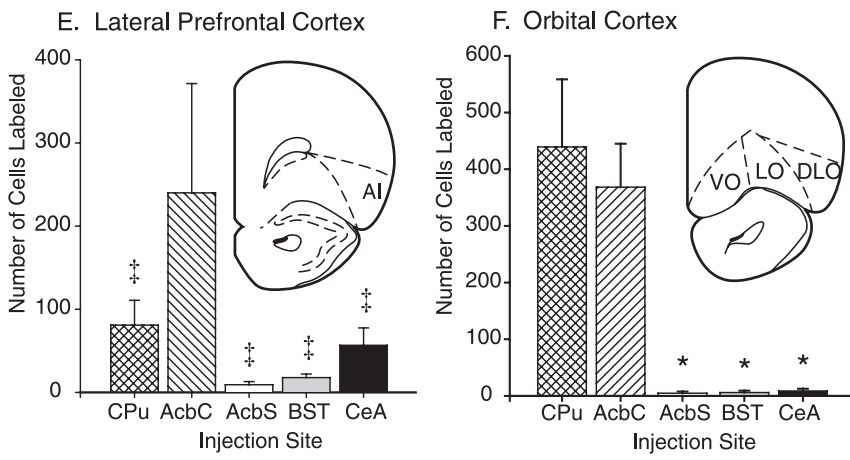

I. Insular Cortex by Subregion
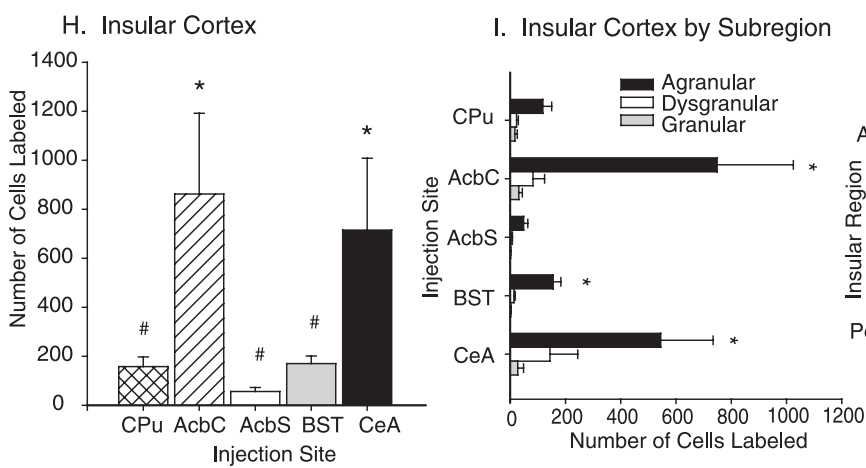

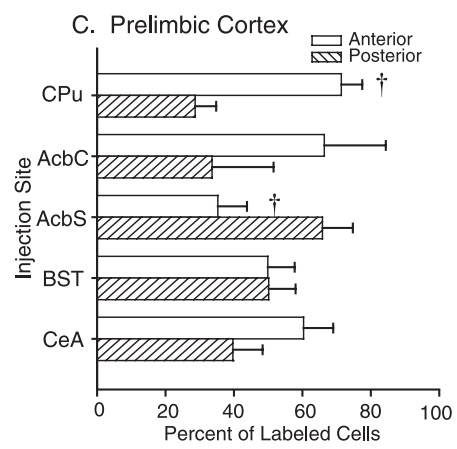

G. Orbital Cortex by Subregion

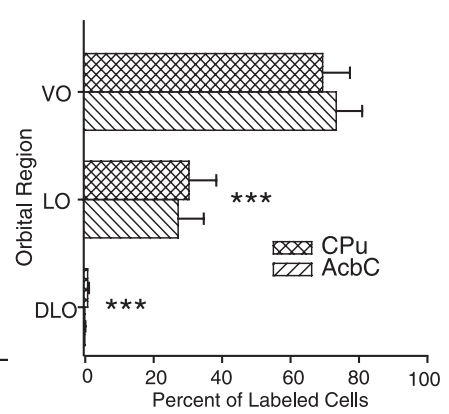

J. Agranular Insular Cortex

Figure 5. Mean ( $\pm S E M)$ retrograde single labeling in prefrontal and insular cortices produced by homotypic and heterotypic pairs of tracer injections in ventral striatal and extended amygdala sites. Within the medial prefrontal cortex, ventral striatal and extended amygdala displayed distinguishing characteristics in the amount of retrograde labeling $(\boldsymbol{A})\left(F_{(4,35)}=5.53 ; p<0.005\right)$, dorsoventral distribution of labeling $(\boldsymbol{B})\left(F_{(12,143)}=12.10 ; p<0.001\right)$, and anteroposterior labeling distribution within prelimbic $(\boldsymbol{C})\left(F_{(4,71)}=6.37 ; p<0.001\right)$ and infralimbic $(\boldsymbol{D})\left(F_{(4,71)}=7.79\right.$; $p<0.001)$ cortices. $\boldsymbol{E}$, AcbC-induced labeling dominated the lateral prefrontal cortex compared with all other sites examined $\left(F_{(4,35)}=5.92 ; p=0.001\right) . F$, (Pu and $A c b C$ injections produced the most labeling in orbital cortex $\left(F_{(4,35)}=10.16 ; p<0.001\right)$, which followed a medial-to-lateral gradient $(\boldsymbol{G})\left(F_{(2,35)}=43.67 ; p<0.001\right)$. Retrograde labeling in the insular cortex was strongest after $A c b C$ and $C e A$ injections $(\boldsymbol{H})\left(F_{(4,35)}=6.42 ; p<0.001\right)$, localized mainly within the agranular insular cortex $(\boldsymbol{I})\left(F_{(2,107)}=38.87 ; p<0.001\right)$, and displayed different anteroposterior labeling distributions for striatal versus extended amygdala injection sites $(J)\left(F_{(8,107)}=4.05 ; p<0.001\right)$. AC, Anterior cingulate; PrC, precentral cortex; PL, prelimbic; IL, infralimbic; DP, dorsal peduncular; $\mathrm{Gl}$, granular insular; DI, dysgranular insular; Al, agranular insular; VO, ventral orbital; LO, lateral orbital; DLO, dorsolateral orbital. $\# p<0.05$ compared with CeA; ${ }^{*} p<0.05$ compared with CPu; ${ }^{* *} p<0.05$ compared with the highest bar for each site; ${ }^{\dagger} p<0.05$ compared with posterior; ${ }^{\ddagger} p<0.05$ compared with $A c b c ;{ }^{* * *} p<0.05$ compared with V0.

afferents of ventral striatopallidum and extended amygdala are relatively segregated along the dorsoventral axis within the medial wall of the hemisphere. Ventral striatopallidal afferents, thought to be involved in reward behavior, originate primarily in dorsal parts of the medial prefrontal cortex. Anterior cingulate cortex, which is reported to temporally sequence responses and attach value to them (Delatour and Gisquet-Verrier, 2001; Rushworth et al., 2004), projects mainly to the CPu site, and prelimbic cortex, which has been shown to weigh action-outcome contingencies and make reward associations (Corbit and Balleine, 2003; Killcross and Coutureau, 2003), primarily targets the AcbC. In contrast, extended amygdala and AcbS receive afferents mainly from ventral medial prefrontal regions, i.e., the infralimbic and dorsal peduncular cortex, which also project strongly to brain- stem sites associated with autonomic function (Groenewegen and Uylings, 2000; Van Eden and Buijs, 2000).

In contrast, the "multimodal" agranular insular cortex, so called because it receives projections representing several sensory modalities relayed through granular and dysgranular insular cortex (Shi and Cassell, 1998a,b), provides abundant afferents to both macrosystems. These, however, arise at different anteroposterior levels of the insula. Extended amygdala and AcbS injections strongly labeled the middle part of the insular cortex, whereas the $\mathrm{CPu}$ and $\mathrm{AcbC}$ injections produced dense labeling in the posterior insular cortex. Interestingly, all of the injection sites evaluated in this study produced moderate, roughly equivalent retrograde labeling in the anterior part of the insular cortex, which is frequently characterized as gustatory or visceral (Braun et al., 
1982; Kosar et al., 1986; Krushel and van der Kooy, 1988) and thought critical to associating incentive values with tastes and odors (Balleine and Dickinson, 2000; Sakai and Imada, 2003; Miranda and McGaugh, 2004). Thus, projections from anterior insular cortex to ventral striatopallidum and extended amygdala may contribute to complex learning and motivation related to tastes and odors. The striking overlap of retrograde labeling produced in the anterior part of the insular cortex by all of the injection sites nonetheless was associated with a near absence of double labeling from heterotypic injection pairs, which is consistent with the idea that outputs from the anterior insular cortex to the two systems emanate from separate cortical networks.

\section{Spread of afferents}

\section{within macrosystems}

Nearly 30 years ago, Yeterian and Van Hoesen (1978) observed in monkey that single loci in the cerebral cortex project to multiple parts of the caudate nucleus. Furthermore, single sites in caudate-putamen receive corticostriatal inputs from multiple, interconnected cortical sites (Yeterian and Van Hoesen, 1978; Reep et al., 2003; Cheatwood et al., 2005). The present study extends the principle underlying those findings to include basal forebrain macrosystems, i.e., ventral striatopallidum and extended amygdala, and demonstrates that the morphological substrates include single cortical neurons with axonal arbors that spread broadly within each macrosystem. Although it is presumed that discrete information so transmitted to multiple sites in macrosystems must, to some extent, become diluted by the local mix of afferents, it nonetheless seems likely that the spread of afferents must also contribute to global activation of macrosystems. Perhaps double labels reflect persistent projections remaining from earlier developmental stages characterized by even more widespread withinmacrosystem corticofugal projections (Christensen et al., 1999).

Ventral striatal injection pairs produced much more double labeling than did extended amygdala pairs, particularly in prefrontal cortex. This indicates that a tendency for cortical afferents to spread within macrosystems is not uniformly expressed throughout the cortex. However, whether this points to differences in how the afferents of different macrosystems are organized or to variability in how projections of different cortical networks are structured requires a more comprehensive examination of the afferents of individual macrosystems.

\section{AcbS as a transition zone}

The AcbS injection sites occupied a caudal dorsomedial part of the shell roughly juxtaposed to the major island of Calleja and notably did not extend into rostral or even middle parts of the shell. This caudomedial part of the shell is generally considered to be part of the ventral striatum (Alheid and Heimer, 1988; Zahm and Brog, 1992) and exhibits striatopallidal features such as strong projections to the ventral pallidum and presence of parvalbumin and choline acetyltransferase immunoreactive interneu-
B. Lateral Prefrontal Cortex C. Orbital Cortex
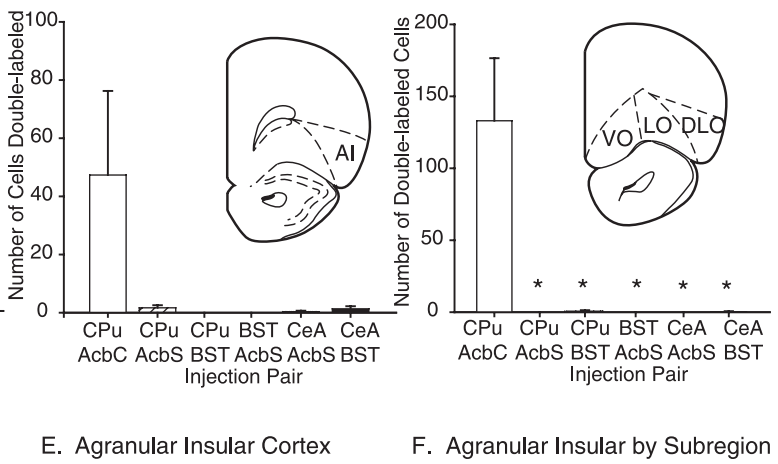

F. Agranular Insular by Subregion
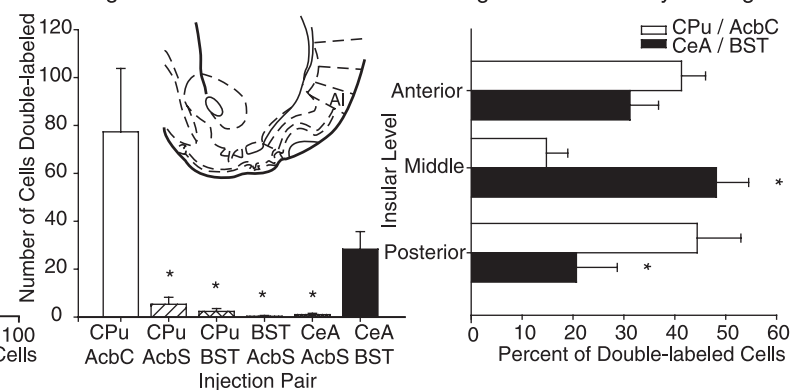

Injection Pai

Figure 6. Mean ( \pm SEM) double labeling produced by injection pairs throughout prefrontal and insular cortices. $C P u-A c b C$ pais signicantly more double labels than any other injection pair in the medial prefrontal cortex $(\boldsymbol{A})\left(F_{(5,17)}=11.60\right.$; prelimbic; IL, infralimbic; DP, dorsal peduncular; Al, agranular insular; V0, ventral orbital; LO, lateral orbital; DLO, dorsolateral orbital. ${ }^{*} p<0.05$ compared with CPu-AcbC group, ${ }^{* *} p<0.05$ compared with V0.

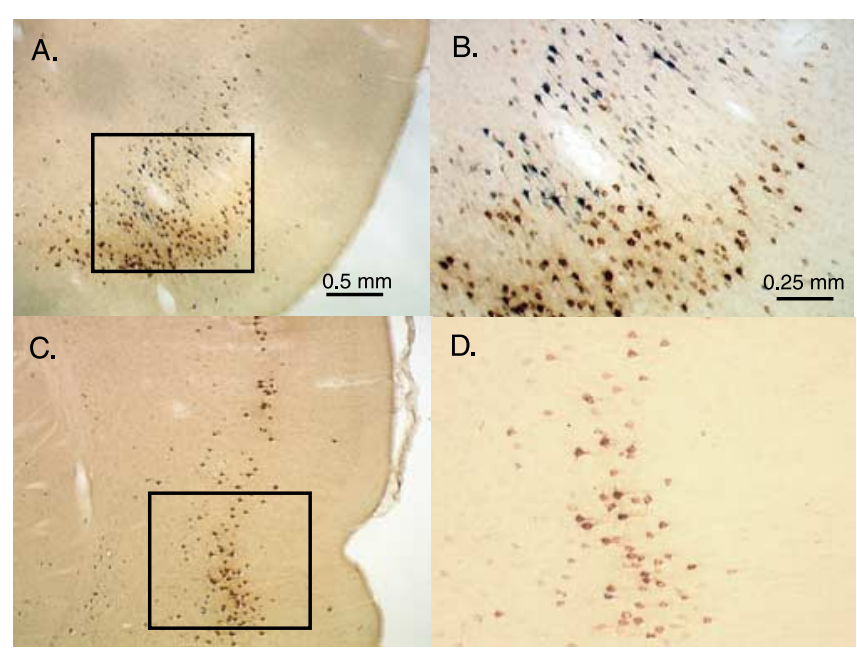

Figure 7. Photomicrographs of retrograde labeling produced in the insular cortex by a CeA$A c b C$ injection pair. $\boldsymbol{A}$, Distribution of single labeling in the rostral insular cortex produced by $C e A$ (black) and AcbC (brown) injections. $\boldsymbol{B}$, Enlargement of $\boldsymbol{A}$. C, Posterior insular level. D, Enlargement of $\boldsymbol{C}$. Note that the distributions of retrogradely labeled neurons produced by the two injections interdigitate and that double-labeled neurons are negligible.

rons (Meredith et al., 1989; Heimer et al., 1991; Zahm and Heimer, 1993; Zahm et al., 2003). However, the AcbS also has features reminiscent of extended amygdala, including projections to lateral hypothalamus and rostral brainstem (Zahm and Heimer, 1993; Usuda et al., 1998), and a variety of neurochemical markers of extended amygdala such as cholecystokinin, angiotensin II, corticotrophin-releasing factor, and oxytocin and vaso- 
A. Prefrontal Cortex

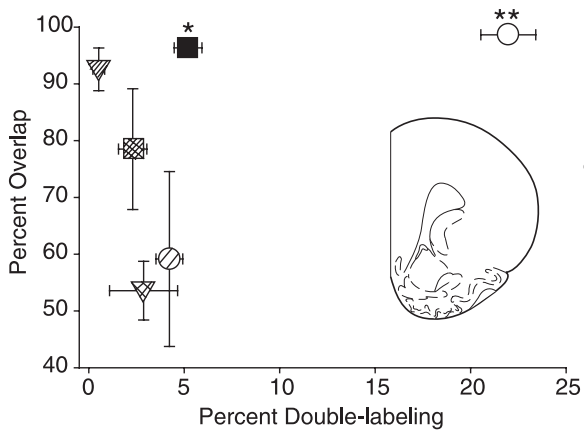

B. Insular Cortex

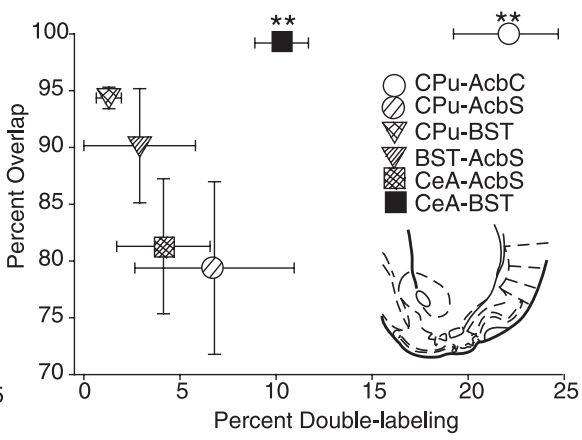

Figure 8. Mean percentage overlap ( \pm SEM) and percentage of double labeling ( \pm SEM) produced by each injection pair. $\boldsymbol{A}$, $\mathrm{CPu}-\mathrm{AcbC}$ and $\mathrm{CeA}-\mathrm{BST}$ pairs showed significantly greater overlap in prefrontocortical retrograde labeling distributions compared with CPu-BST, $C P u-A c b S$, or CeA-AcbS pairs $\left(F_{(5,35)}=6.70 ; p<0.001\right)$, but only $C P u-A c b C$ pairs also showed greater double labeling $\left(F_{(5,35)}=27.96 ; p<0.001\right)$. B, In the insular cortex, both $C P u-A c b C$ and CeA-BST pairs produced high overlap $\left(F_{(5,35)}=5.81 ; p<0.001 ; p<0.05\right)$ and double labeling $\left(F_{(5,35)}=6.34 ; p<0.001\right)$ compared with CPu-AcbS and CeA-AcbS pairs. ${ }^{*} p<0.05$ for overlap; ${ }^{* *} p<0.05$ for overlap and double labeling.

pressin receptors (Merchenthaler, 1984; Zaborszky et al., 1985; Alheid and Heimer, 1988; Veinante and Freund-Mercier, 1997). This combination of properties has led to the proposition that the caudomedial shell is a "transition area" reflecting the merged functional-anatomical qualities of striatopallidum and extended amygdala (Alheid and Heimer, 1988; Alheid et al., 1994; Heimer et al., 1997a,b). However, the present data indicate that many fewer prefrontal and insular cortical neurons project to the AcbS than to $\mathrm{CPu}, \mathrm{AcbC}$, BST, or CeA, suggesting that the influences of these projections are lesser in AcbS than in these other structures. Although the mostly infralimbic and midlevel insular distribution of the few AcbS-projecting neurons most overlapped with that of extended amygdala, AcbS injections produced minimal double labeling only when paired with a $\mathrm{CPu}$ site. Thus, the present analysis also appears to identify both striatopallidal and extended amygdaloid properties within the caudomedial accumbens shell and thus neither strongly confirms nor refutes the point of view that the AcbS is a transition zone. Nonetheless, the overall neurochemical and hodological complexion of the AcbS is sufficiently distinct that it seems quite reasonable to regard it as a unique processing region, particularly because this assessment is supported by studies of emotional and motivational behaviors (Zimmermann et al., 1999; Reynolds and Berridge, 2002).

\section{Significance}

The present data suggest that the modular organization of the basal forebrain, expressed as macrosystems, is reflected in a corresponding differentiation of output neurons in the prefrontal and insular cortices. Thus, a capacity of the macrosystems for independent processing of information is an extension of the segregation of cortical networks. The implication emerges that these potentially tightly interconnected cortical and subcortical structures have developed and, possibly, evolved in tandem.

Behavioral flexibility would be expected to require neural substrates with both a wide range of inputs and a significant capacity to specify adaptive actions. Segregation of corticosubcortical information transfer along lines observed in this study would allow for functionally distinct macrosystems to efficiently sculpt behavior in relation to cortical representations of an organism's current and relevant past circumstances. To illustrate with an oversimplification, the observed segregation of connections may facilitate execution of goal-oriented, reward-incentive behavior under the control of ventral striatopallidum with limited distraction from extended amygdaloid influences dedicated to fear, stress, and autonomic regulation but still permit extended amygdala output, competing in parallel, to overtake control of behavior if conditions warrant. This kind of processing could contribute to the capacity to experience ambiguous circumstances, such as tasting a bittersweet drink or giving a talk, as simultaneously and separately both rewarding and stressful, and to respond accordingly.

\section{Conclusions}

The present study elucidates key organizational principles of macrosystem cortical afferents. Ventral striatopallidum and extended amygdala receive separate sets of afferents from prefrontal and insular cortices. In contrast, projections from these cortical areas spread broadly within macrosystems, consistent with the possibility that they contribute to global macrosystem activation.

\section{References}

Alheid GF (2003) Extended amygdala and basal forebrain. Ann NY Acad Sci 985:185-205.

Alheid GF, Heimer L (1988) New perspectives in basal forebrain organization of special relevance for neuropsychiatric disorders: the striatopallidal, amygdaloid, and corticopetal components of substantia innominata. Neuroscience 27:1-39.

Alheid GF, de Olmos JS, Beltramino C (1995) Amygdala and extended amygdala. In: The rat nervous system, Ed 2 (Paxinos G, ed), pp 495-578. San Diego: Academic.

Alheid GF, Beltramino C, Braun A, Miselis RR, François C, de Olmos JS (1994) Transition areas of the striatopallidal system and extended amygdala in the rat and primate: observations from histochemistry and experiments with mono- and transsynaptic tracer. In: The basal ganglia IV, Vol 41, New ideas and data on structure and function (Percheron G, McKenzie JS, Féger J, eds), pp 95-107. New York: Plenum.

Arikuni T, Sakai M, Kubota K (1983) Columnar aggregation of prefrontal and anterior cingulate cortical cells projecting to the thalamic mediodorsal nucleus in the monkey. J Comp Neurol 220:116-125.

Aston-Jones G, Rajkowski J, Cohen J (1999) Role of locus coeruleus in attention and behavioral flexibility. Biol Psychiatry 46:1309-1320.

Balleine BW, Dickinson A (2000) The effect of lesions of the insular cortex on instrumental conditioning: evidence for a role in incentive memory. J Neurosci 20:8954-8964.

Berendse HW, Galis-de Graaf Y, Groenewegen HJ (1992) Topographical organization and relationship with ventral striatal compartments of prefrontal corticostriatal projections in the rat. J Comp Neurol 316:314-347.

Braun JJ, Lasiter PP, Kiefer SW (1982) The gustatory neocortex of the rat. Physiol Psychol 10:13-45.

Brog JS, Salyapongse A, Deutch AY, Zahm DS (1993) The patterns of afferent innervation of the core and shell in the "accumbens" part of the rat ventral striatum: immunohistochemical detection of retrogradely transported fluoro-gold. J Comp Neurol 338:255-278.

Bugbee NM, Goldman-Rakic PS (1983) Columnar organizationn of corticocortical projections in squirrel and rhesus monkeys: similarity of columns in species differing in cortical volume. J Comp Neurol 220:355-364.

Burwell RD (2001) Borders and cytoarchitecture of the perirhinal and postrhinal cortices in the rat. J Comp Neurol 437:17-41.

Carmichael ST, Price JL (1995) Limbic connections of the orbital and medial prefrontal cortex in macaque monkeys. J Comp Neurol 363:615-641.

Carmichael ST, Price JL (1996) Connectional networks within the orbital and medial prefrontal cortex of macaque monkeys. J Comp Neurol 371:179-207.

Cheatwood JL, Corwin JV, Reep RL (2005) Overlap and interdigitation of cortical and thalamic afferents to dorsocentral striatum in the rat. Brain Res 1036:90-100. 
Christensen J, Sorensen JC, Ostergaard K, Zimmer J (1999) Early postnatal development of the rat corticostriatal pathway: an anterograde axonal tracing study using biocytin pellets. Anat Embryol (Berl) 200:73-80.

Corbit LH, Balleine BW (2003) The role of prelimbic cortex in instrumental conditioning. Behav Brain Res 146:145-157.

Delatour B, Gisquet-Verrier P (2001) Involvement of the dorsal anterior cingulate cortex in temporal behavioral sequencing: subregional analysis of the medial prefrontal cortex in rat. Behav Brain Res 126:105-114.

Eslinger PJ, Grattan LM (1993) Frontal lobe and frontal-striatal substrates for different forms of human cognitive flexibility. Neuropsychologia $31: 17-28$

Floyd NS, Price JL, Ferry AT, Keay KA, Bandler R (2000) Orbitomedial prefrontal cortical projections to distinct longitudinal columns of the periaqueductal gray in the rat. J Comp Neurol 422:556-578.

Floyd NS, Price JL, Ferry AT, Keay KA, Bandler R (2001) Orbitomedial prefrontal cortical projections to hypothalamus in the rat. J Comp Neurol 432:307-328.

Groenewegen HJ, Uylings HB (2000) The prefrontal cortex and the integration of sensory, limbic and autonomic information. Prog Brain Res 126:3-28.

Groenewegen HJ, Berendse HW, Wolters JG, Lohman AH (1990) The anatomical relationship of the prefrontal cortex with the striatopallidal system, the thalamus and the amygdala: evidence for a parallel organization. Prog Brain Res 85:95-116; discussion 116-118.

Groenewegen HJ, Wright CI, Uylings HB (1997) The anatomical relationships of the prefrontal cortex with limbic structures and the basal ganglia. J Psychopharmacol 11:99-106.

Habib M (2004) Athymhormia and disorders of motivation in basal ganglia disease. J Neuropsychiatry Clin Neurosci 16:509-525.

Heimer L (2003) A new anatomical framework for neuropsychiatric disorders and drug abuse. Am J Psychiatry 160:1726-1739.

Heimer L, Wilson RD (1975) The subcortical projections of allocortex: similarities in the neuronal associations of the hippocampus, the piriform cortex and the neocortex. In: Golgi centennial symposium proceedings (Santini M, ed), pp 177-193. New York: Raven.

Heimer L, Zahm DS, Churchill L, Kalivas PW, Wohltmann C (1991) Specificity in the projection patterns of accumbal core and shell in the rat. Neuroscience 41:89-125.

Heimer L, Harlan RE, Alheid GF, Garcia MM, de Olmos JS (1997a) Substantia innominata: a notion which impedes clinical-anatomical correlations in neuropsychiatric disorders. Neuroscience 76:957-1006.

Heimer L, Alheid GF, de Olmos JS, Groenewegen HJ, Haber SN, Harlan RE, Zahm DS (1997b) The accumbens: beyond the core-shell dichotomy. J Neuropsychiatry Clin Neurosci 9:354-381.

Holstege G (1989) Descending motor pathways and the spinal motor system: limbic and non-limbic components Prog Brain Res 87:307-421.

Holstege G (1992) The emotional motor system. Eur J Morphol 30:67-79.

Holstege G, Bandler R, Saper CB (1996) Progress in brain research, Vol 107, The emotional motor system. Amsterdam: Elsevier.

Hubel DH, Wiesel TN (1962) Receptive fields, binocular interactions and functional architecture in the cat's visual cortex. J Physiol (Lond) 160:106-154.

Jones BF, Groenewegen HJ, Witter MP (2005) Intrinsic connections of the cingulate cortex in the rat suggest the existence of multiple functionally segregated networks. Neuroscience 133:193-207.

Kalivas PW, Barnes CD (1993) Limbic motor circuits and neuropsychiatry. Boca Raton, FL: CRC.

Kelley AE, Domesick VB, Nauta WJ (1982) The amygdalostriatal projection in the rat—an anatomical study by anterograde and retrograde tracing methods. Neuroscience 7:615-630.

Killcross S, Coutureau E (2003) Coordination of actions and habits in the medial prefrontal cortex of rats. Cereb Cortex 13:400-408.

Kosar E, Grill HJ, Norgren R (1986) Gustatory cortex in the rat. I. Physiological properties and cytoarchitecture. Brain Res 379:329-341.

Krettek JE, Price JL (1977) The cortical projections of the mediodorsal nucleus and adjacent thalamic nuclei in the rat. J Comp Neurol 171:157-191.

Krushel LA, van der Kooy D (1988) Visceral cortex: integration of the mucosal senses with limbic information in the rat agranular insular cortex. J Comp Neurol 270:39-54, 62-63.

MacLean PD (1989) The triune brain in evolution: role in paleocerebral functions. New York: Plenum.
McDonald AJ (1998) Cortical pathways to the mammalian amygdala. Prog Neurobiol 55:257-332.

McDonald AJ, Mascagni F, Guo L (1996) projections of the medial and lateral prefrontal cortices to the amygdala: a Phaseolus vulgaris leucoagglutinin study in the rat. Neuroscience 71:55-75.

McDonald AJ, Shammah-Lagnado SJ, Shi C, Davis M (1999) Cortical afferents to the extended amygdala. Ann NY Acad Sci 877:309-338.

McDonald BC, Flashman LA, Saykin AJ (2002) Executive dysfunction following traumatic brain injury: neural substrates and treatment strategies. NeuroRehabilitation 17:333-344.

McGeorge AJ, Faull RLM (1989) The organization of the projection from the cerebral cortex to the striatum in the rat. Neuroscience 29:503-537.

McGinty JF (1999) Advancing from the ventral striatum to the extended amygdala. Implications for neuropsychiatry and drug abuse. Introduction. Ann N Y Acad Sci 877:xii-xv.

McIntyre DC, Kelly ME, Staines WA (1996) Efferent projections of the anterior perirhinal cortex in the rat. J Comp Neurol 369:302-318.

Merchenthaler I (1984) Corticotropin releasing factor (CRF)-like immunoreactivity in the rat central nervous system. Extrahypothalamic distribution. Peptides 5:53-69.

Meredith GE, Blank B, Groenewegen HJ (1989) The distribution and compartmental organization of the cholinergic neurons in nucleus accumbens of the rat. Neuroscience 31:327-345.

Mesulam M-M (1990) Large-scale neurocognitive networks and distributed processing for attention, language and memory. Ann Neurol 28:597-613.

Miranda MI, McGaugh JL (2004) Enhancement of inhibitory avoidance and conditioned taste aversion memory with insular cortex infusions of 8-Br-cAMP: involvement of the basolateral amygdala. Learn Mem 11:312-317.

Mountcastle VB (2003) Introduction. Computation in cortical columns. Cereb Cortex 13:2-4.

Napier TC, Kalivas PW, Hanin I (1991) The basal forebrain: anatomy to function. New York: Plenum.

Öngür D, Price JL (2000) The organization of networks within the orbital and medial prefrontal cortex of rats, monkeys and humans. Cereb Cortex 10:206-219.

Paxinos G, Watson C (1998) The rat brain in stereotaxic coordinates, Ed 4. San Diego: Academic.

Reep RL, Cheatwood JL, Corwin JV (2003) The associative striatum: organization of cortical projections to the dorsocentral striatum in rats. J Comp Neurol 467:271-292.

Reynolds SM, Berridge KC (2002) Positive and negative motivation in nucleus accumbens shell: bivalent rostrocaudal gradients for GABA-elicited eating, taste "liking"/“disliking" reactions, place preference/avoidance, and fear. J Neurosci 22:7308-7320.

Rushworth MF, Walton ME, Kennerley SW, Bannerman DM (2004) Action sets and decisions in the medial frontal cortex. Trends Cogn Sci 8:410-417.

Sakai N, Imada S (2003) Bilateral lesions of the insular cortex or of the prefrontal cortex block the association between taste and odor in the rat. Neurobiol Learn Mem 80:24-31.

Shi CJ, Cassell MD (1998a) Cortical, thalamic, and amygdaloid connections of the anterior and posterior insular cortices. J Comp Neurol 399:440-468.

Shi CJ, Cassell MD (1998b) Cascade projections from somatosensory cortex to the rat basolateral amygdala via the parietal insular cortex. J Comp Neurol 399:469-491.

Swanson LW (2000) Cerebral hemisphere regulation of motivated behavior. Brain Res 886:113-164.

Swanson LW (2003) The amygdala and its place in the cerebral hemisphere. Ann NY Acad Sci 985:174-184.

Usuda I, Tanaka K, Chiba T (1998) Efferent projections of the nucleus accumbens in the rat with special reference to subdivision of the nucleus: biotinylated dextran amine study. Brain Res 797:73-93.

Van Eden CG, Buijs RM (2000) Functional neuroanatomy of the prefrontal cortex: autonomic interactions. Prog Brain Res 126:49-62.

Van Eden CG, Uylings HB (1985) Cytoarchitectonic development of the prefrontal cortex in the rat. J Comp Neurol 241:253-267.

Veinante P, Freund-Mercier MJ (1997) Distribution of oxytocin- and 
vasopressin-binding sites in the rat extended amygdala: a histoautoradiographic study. J Comp Neurol 383:305-325.

Wolters EC (2000) Psychiatric complications in Parkinson's disease. J Neural Transm [Suppl] 60:291-302.

Yeterian EH, Van Hoesen GW (1978) Cortico-striate projections in the rhesus monkey: the organization of certain cortico-caudate connections. Brain Res 139:43-63.

Zaborszky L, Alheid GF, Beinfeld MC, Eiden LE, Heimer L, Palkovits M (1985) Cholecystokinin innervation of the ventral striatum: a morphological and radioimmunological study. Neuroscience 14:427-453.

Zahm DS (1998) Is the caudomedial shell of the nucleus accumbens part of the extended amygdala? A consideration of connections. Crit Rev Neurobiol 12:245-265.

Zahm DS (2000) An integrative neuroanatomical perspective on some subcortical substrates of adaptive responding with emphasis on the nucleus accumbens. Neurosci Biobehav Rev 24:85-105.
Zahm DS (2005) The evolving theory of basal forebrain functionalanatomical "macrosystems." Neurosci Biobehav Rev, in press.

Zahm DS, Brog JS (1992) Commentary: on the significance of the coreshell boundary in the rat nucleus accumbens. Neuroscience 50: 751-767.

Zahm DS, Heimer L (1993) Specificity in the efferent projections of the nucleus accumbens in the rat: comparison of the rostral pole projection patterns with those of the core and shell. J Comp Neurol 327:220-232.

Zahm DS, Grosu S, Irving JC, Williams EA (2003) Discrimination of striatopallidum and extended amygdala in the rat: a role for parvalbumin immunoreactive neurons? Brain Res 978:141-154.

Zimmermann P, Privou C, Huston JP (1999) Differential sensitivity of the caudal and rostral nucleus accumbens to the rewarding effects of a H1histaminergic receptor blocker as measured with place-preference and self-stimulation behavior. Neuroscience 94:93-103. 